\title{
Las industrias convergentes y la ópera en los cines: de espectáculo tecnológico a evento mediático
}

\section{Convergent industries and the opera in theaters: from a technology show to a new mediatic event}

\author{
Isabel Villanueva Benito \\ Profesora Contratada Doctor, \\ Facultad de Ciencias de la Comunicación \\ (Universitat Internacional de Catalunya) \\ Iván Lacasa-Mas \\ Profesor Titular, \\ Facultad de Ciencias de la Comunicación \\ (Universitat Internacional de Catalunya)
}

Fecha de recepción: 15 de abril de 2016

Fecha de revisión: 10 de agosto de 2016

Para citar este artículo: Villanueva Benito, I. y Lacasa-Mas, I. (2017): Las industrias convergentes y la ópera en los cines: de espectáculo tecnológico a evento mediático, Icono 14, volumen 15 (1), pp. 1-20. doi: 10.7195/ri14. v15i2.979 


\section{Resumen}

Después de diez años, el cine y la ópera han consolidado un espectáculo en expansión global. Tras haber definido, en esta misma revista científica (2012), las características tecnológicas y comerciales que hacian de estas retransmisiones productos audiovisuales sostenibles, nuestro interés se centra ahora en conocer cuáles son las propiedades identitarias que, tras una década, han convertido a la ópera en los cines en un evento mediático nuevo y distinto en términos sociológicos. Superada una perspectiva principalmente tecnológica, el objetivo de esta investigación es, mediante una combinación de metodologías, (a) estudiar las particularidades de los eventos mediáticos operísticos, para (b) explicar algunos de los cambios en los comportamientos sociológicos de sus públicos. Nuestro segundo estudio constata que estos espectáculos abren un "espacio entre convenciones" que brinda una gran oportunidad a ambas industrias culturales para dialogar con nuevas audiencias.

Palabras clave: Cine - Ópera - Industrias Culturales - Mercados convergentes - Mediatización - Audiencias - Medios Audiovisuales - Artes Escénicas

\section{Abstract}

In ten years cinema and opera have come together to create an show that's growing globally. After defining the technological and commercial characteristics that made these broadcasted events a sustainable audiovisual product - in this very same journal (2012) - our interest is now focused on getting to know the identifying characteristics that have, a decade later, turned opera in movie theaters into a distinctively new media event, in sociological terms. A mostly technological perspective having been overcome, the goal of this research, through a combination of methodologies, is to (a) study the particularities of opera media events, in order to (b) explain some of the behavioral changes of their audiences. Our second study notes that these events are carving their own "niche among conventions," which offers a huge opportunity for both cultural industries to engage in dialogue with new audiences.

Key Words: Cinema - Opera, Cultural Industries - Converging Markets - Mediatization - Audiences - Audiovisual Media - Performing Arts 
Las industrias convergentes y la ópera en los cines... $\mid 3$

INNOVACIÓN TEÓRICA

\section{Introducción}

Durante la última década, numerosos estudios han centrado su atención en los cambios profundos que la digitalización ha provocado en la industria cinematográfica (Rombes, 2009; Zallo, 2011). Por nuestra parte, en el año 2012 ya analizamos, en esta misma revista científica, una de las principales estrategias que el cine había puesto en marcha para renovar el sector de la exhibición. El artículo profundizaba en las características de la ópera retransmitida en los cines, por aquel entonces un modelo de negocio global nuevo que trataba de consolidar una oferta de contenidos alternativos en las salas cinematográficas (Husak, 2004, p. 291; Vladica \& Davis, 2013, p. 3) ${ }^{1}$. En 2016 se cumplen 10 años de esa iniciativa, que finalmente ha alcanzado un gran éxito económico y tecnológico. Como ya se intuía hace cuatro años, las retransmisiones de ópera en vivo en las salas de cine han generado un mercado consolidado y en auge. El negocio, implantado hoy en más de 2700 cines de todo el mundo, es considerado el buque insignia de una revolución artístico-tecnológica, al haber logrado crear un nuevo mercado de consumo cultural (Opera Actual, 2015). La ópera en los cines ha sido capaz de impulsar un modelo mediático que ha revalorizado el sentido de los espectáculos colectivos (Lipovetsky \& Serroy, 2009, p. 65; Zallo, 2011), unos espectáculos que ciertos autores piensan que ya han alcanzado la condición de evento mediático. Este concepto, ampliamente desarrollado en la literatura especializada, describe la ceremonia creada en torno a un acontecimiento mediatizado que es "capaz de interrumpir el flujo de la vida diaria de los espectadores y provocar la respuesta de una audiencia comprometida" (Dayan \& Katz, 1992, p. 14). El evento mediático queda inscrito, así, en los "intereses sociales, económicos y culturales de los ciudadanos, transformando sus sistemas de expectativas" (Charaudeau, 2006, p. 53). Aplicado a la retransmisión de la ópera en los cines, el concepto de evento mediático hace referencia al encuentro en un espacio público - una sala de cine- en el que se disfruta de una producción que originariamente tiene lugar en otro espacio público —un teatro- (Marriot, 2007, pp. 73-87). Asimismo, tiene en cuenta, tanto los procesos de creación y de retransmisión que son empleados para ofrecer un espectáculo sincronizado con otro del que queda separado geográficamente, como la respuesta del público asistente (Steichen, 2009, pp. 24-30; Speed, 2012, p. 2). Es en este público asistente en el que debería centrarse la investigación para averiguar si, tras una década de transición artístico-tecnológica, las propiedades que presentan las retransmisiones de ópera en cines le está permitiendo encontrar una nueva y distinta 
oportunidad de recrearse, cultivarse y socializarse. Este trabajo pretende ser un paso en esa dirección. Su relevancia es clara: si se constata que el evento mediático operístico va congregando y fidelizando a una audiencia propia y distinta, con comportamientos nuevos, podrá concluirse que la consolidación de dicho evento en el contexto artístico está en camino de quedar garantizada (Vladica \& Davis, 2013, p. 5).

\section{Método}

Para alcanzar nuestro objetivo hemos dividido el análisis en dos partes y hemos acudido a una combinación de metodologías. En la primera parte (apartado 3) hemos identificado las principales características identitarias de la ópera en los cines. En la segunda (apartado 4) hemos descrito los principales cambios sociológicos que estas características están favoreciendo. Para identificar los rasgos que definen este negocio global hemos llevado a cabo una vasta consulta de fuentes bibliográficas y de abundante material hemerográfico de actualidad, así como un seguimiento de las acciones públicas de los teatros y organismos culturales - tales como 0pera Europa, Opera America, The Metropolitan Opera House de Nueva York o empresas intermediarias como Rising Alternative-. Con respecto al estudio de los cambios sociológicos, hemos recogido los principales resultados de múltiples investigaciones internacionales centradas en el análisis de las audiencias de la ópera en los cines (Sheppard, 2007; Swanson, Davis \& Zhao, 2008; Anderson, 2011; Zomerdijk \& Voss, 2011; Steichen, 2011, pp. 443-459; Speed, 2012; Vladica \& Davis, 2013).

\section{Características propias de la ópera retransmiti- da en los cines}

En los últimos años, numerosos autores han tratado de analizar las características especiales de las retransmisiones operísticas en directo, conocidas como Live in HD o Digital Broadcast Cinema ${ }^{2}$ (Sheppard, 2007, pp. 383- 387) 3 $^{3}$ La ópera en directo proyectada en los cines se considera un fenómeno artístico único, al haber adquirido una identidad institucional propia, gracias a la convergencia de los dos sectores que lo definen, el cinematográfico y el operístico (Cashin, 2010). El artificio mediático cierra una alianza cultural con los públicos, al crear un producto dis- 
tinto y más popular, compatible con la representación original en directo (Steichen 2011, pp. 446, 454). Para esclarecer en qué medida la ópera en los cines puede estar cambiando la apreciación del arte que experimentan los públicos, primero hay que entender mejor su personalidad cultural diferenciada, es decir, profundizar en algunas de las características centrales que la distinguen: 1) la omnipresencia tecnológica, 2) la recreación audiovisual del vivo y 3) el enfoque comercial empleado.

\subsection{Omnipresencia tecnológica}

Una de las principales propiedades de este fenómeno cinematográfico es la incorporación de una mirada tecnológica en todos los procesos de creación y difusión del espectáculo, como vía para acercar el espectáculo original -la ópera en los teatros- a las audiencias de las salas exhibidoras, emular su aura y respetar su esencia artística (Morris, 2010, pp. 96-119). A ojos de muchos de sus impulsores, las producciones de ópera millonarias y sobresalientes, como las que puede ofrecer el Metropolitan Opera House de Nueva York (Met), combinadas con las pantallas gigantes de los cines y los sistemas de sonido especializado (Dolby Digital, Sony Dynamic, Digital Sound o Digital Theater System, entre otros), convierten a estos espectáculos en el fenómeno artístico más cercano a la ópera original en vivo del que se dispone (Anderson, 2011, p. 7). Diferentes autores consideran que la experiencia que produce en los espectadores no es sustituta pero sí sucesora de la vivida en los teatros (Jacob, 2006). Gracias al uso de la tecnología se deja de depender de los condicionantes geográficos y se consigue llegar hasta amplias y lejanas audiencias (Steichen, 2011, p. 445). El uso de la tecnología digital extiende, por un lado, la corporalidad del artista y potencia la imaginación del público; por el otro, reduce y limita la capacidad que ambos tenían de conectar físicamente en el teatro (Shaw, 2008, p. 91).

Además, la ópera mediatizada no solo incorpora el enfoque tecnológico en el proceso de difusión del espectáculo, sino que también lo hace en los procesos de creación y de comercialización del mismo. Bastan, como ejemplos, el empleo de trece cámaras de televisión robotizadas, en teatros como The English National Opera (ENO), el Met, o el Teatro Real de Madrid, para favorecer la visión privilegiada del espectáculo durante las emisiones; o las partidas presupuestarias destinadas a 


\section{INNOVACIÓN TEÓRICA}

actividades digitales complementarias, tales como el acceso a las producciones en directo desde las páginas web de los teatros, o las suscripciones a otros servicios, como el streaming (The Metropolitan Opera House, 2012, pp. 3-4; Speed, 2012, p. 3) . $^{5}$

La mirada tecnológica de la ópera en los cines parte de las prácticas y oficios heredados de las retransmisiones para televisión iniciadas en los años 50, así como de estrategias educativas que muchos teatros han llevado a cabo en las últimas décadas (Barnes, 2003) ${ }^{6}$. Hoy resurgen gracias a la difusión de los espectáculos en tiempo real vía satélite (D'Agostino, 2010).

De hecho, son los evidentes retos técnicos o, en ocasiones, los errores apreciables que se derivan del uso en tiempo real de la tecnología avanzada, los que hacen recordar al público su condición de espectadores virtuales. Con frecuencia, el espectador asocia los visionados en el cine más con la apreciación doméstica de un espectáculo televisado en alta calidad que con el visionado de una película en la sala cinematográfica: gracias a la tecnología, los miembros del público son capaces de comprometerse con el evento original en directo, al tiempo que, como sucede en la televisión, perciben que están separados de él. La conciencia de una mediación puede llevarles a ver el espectáculo en vivo como un producto aspiracional y a desear vivirlo en el teatro (Anderson, 2011, p. 6).

\subsection{Recreación audiovisual del vivo}

Los teóricos que en los últimos años han abordado cuestiones estéticas sobre este tipo de retransmisiones han recogido las preocupaciones en torno a la reinterpretación del espectáculo en vivo que implican. La segunda característica del Live in $H D$ tiene que ver, precisamente, con la forma en que el lenguaje audiovisual recrea el espectáculo original. La mediatización que implica este tipo de contenidos mostrados en pantalla gigante sofistica y engrandece de tal modo el acto de apreciación de la obra de arte, que ya no puede hablarse de la asistencia física al teatro de ópera en términos de ventaja (Horowitz, 2009, pp. 6-14).

Según los autores, la experiencia del vivo es recreada en los cines cuando las audiencias se sienten copresentes y copartícipes del espectáculo original en directo 
(Heyer, 2008, pp. 591-604). En consecuencia, para que el vivo pueda ser emulado en términos artísticos, ha de combinar los procesos y lenguajes de la filmación en directo con la capacidad que las audiencias tienen de interactuar y responder a esos procesos fílmicos (Anderson, 2011, p. 5).

La tecnología y el lenguaje audiovisuales, por tanto, son factores determinantes a la hora de conseguir que los públicos que están en el cine participen y se comprometan con el espectáculo original que está sucediendo simultáneamente (Vladica \& Davis, 2013, pp. 2-3). Peter Gelb, cofundador del proyecto del Met, explica que, en su concepción originaria, los productos operísticos en live in $H D$ no habían sido pensados como películas, pero tampoco intentaban trasplantar estrictamente el espectáculo original (Steichen, 2011, pp. 444, 445). De forma novedosa, la ópera proyectada en los cines también incorpora estéticas y lenguajes propios de las retransmisiones televisivas en directo ${ }^{7}$. Gracias a técnicas que favorecen una visión totalizada del evento y una sincronización temporal con el espectáculo, los espectadores aprecian la complejidad y la dimensión global del arte operístico (Bolter, 2005, p. 10; Steichen, 2011, p. 446) ${ }^{8}$.

Por otro lado, se ha comprobado que el cine no solo ofrece un fórum físico apropiado - la sala-, sino también que ejerce, en tanto que medio, una influencia sobre el propio arte (Johnson, 2008). Esta influencia favorece la aceptación por parte de los públicos, en el caso del Live in $H D$, de la indivisibilidad entre el espectáculo en vivo y su producto mediatizado, de modo que, en los cines se crea una experiencia audiovisual distinta y novedosa. Podría entenderse, por tanto, que dicha indivisibilidad entre el espectáculo original y el proceso de interpretación audiovisual ha conseguido diversificar la oferta audiovisual de la ópera, al ofrecer un producto cuyo resultado no podría obtenerse sin uno de los dos procesos creativos, el mediatizado y el original (Villanueva, 2014, pp. 205-242). Muchos realizadores del teatro, de hecho, consideran que la apreciación de la ópera en los cines puede llegar a ser mejor que la propia representación en vivo, pues potencia las condiciones de visión, sin perder las cualidades de la retransmisión en directo (Steichen, 2011, pp. 444-445). Resulta lógico, ya que las retransmisiones en HD pueden ofrecer, entre otras ventajas, una visión privilegiada del espectáculo, la captación de lo importante de la narración sin las posibles distracciones que pueden darse en el 


\section{INNOVACIÓN TEÓRICA}

teatro, el uso de equipos pequeños y discretos de grabación que permiten una mayor movilidad, o la muestra de la tecnología como parte integrante del fenómeno artístico (Anderson, 2011, p. 7) .

\subsection{Visión comercial del espectáculo}

Otra de las características que se considera definitoria del nuevo modelo de negocio operístico audiovisual es la visión comercial con la que se concibe el espectáculo. A diferencia de la ópera audiovisual del siglo XX (ópera filmada, televisiónópera, vídeo-ópera...), la retransmitida en los cines se planifica, desde el inicio, para un consumo prolongado en el tiempo a través de otras plataformas, como el vídeo bajo demanda (VOD) o el streaming online mediante suscripción (Steichen, 2009, pp. 24-30).

Este enfoque comercial que dirige tanto la concepción creativa de la obra como los sistemas de producción artística empleados en ella, se aprecia en elementos como los contenidos musicales extra, la creación de un star system propio, o el tipo de repertorio que se programa (Morris, 2010, pp. 96-119). En relación a los contenidos adicionales, todas las proyecciones de ópera incorporan cápsulas audiovisuales complementarias a la narración musical, que se proyectan en los tiempos de descanso, tales como las entrevistas a los artistas en el intermedio musical o el acceso en directo al backstage. Estos contenidos adicionales alimentan el interés de las audiencias y fortalecen sus nexos de unión no solo con el arte operístico, sino con sus estrellas y divos.

Otra de las características comerciales es, precisamente, la integración del star system dentro de la estructura del propio espectáculo. Para la mayor parte de los cantantes, la participación en las retransmisiones supone una meta aspiracional, dada la oportunidad que les brinda de engrandecer su fama internacional. A muchos de ellos, además de como cantantes, les permite colaborar como presentadores o representantes del propio teatro en otros ámbitos comerciales (Anderson, 2011, p.7). Aunque muchos de estos cantantes manifiestan el desagrado que les causa la constante presión que la filmación ejerce sobre su trabajo (Speed, 2012, pp. 49, 53), también reconocen que la plataforma publicitaria a gran escala que les ofrece 
aumenta significativamente el número de fans. Gracias a la ópera retransmitida en los cines consiguen integrarse en un negocio y en un tipo de contratación que no se reduce a la representación en directo, sino que, muchas veces, se extiende a otras ventanas de explotación; es lo que sucede en el caso de la grabación de la obra en DVD, por ejemplo. La estrategia de negocio operístico involucra a sus divos en iniciativas transmediáticas orientadas a aumentar los beneficios económicos y a mejorar la visibilidad mundial de los espectáculos.

Con respecto al repertorio escogido para las programaciones, debe resaltarse la apuesta casi exclusiva por títulos mainstream, dirigida por el criterio de atracción de audiencias masivas, mundiales y mediáticas. Aunque desde 2006 la ópera en los cines ha querido impulsar también producciones más desconocidas y minoritarias, los datos de taquilla han revelado que las audiencias prefieren programaciones convencionales que contengan títulos clásicos, de compositores como Verdi, Puccini, Bizet, Rossini, Mozart, Strauss o Wagner (The Metropolitan Opera House, 2010, pp. 7- 20; Speed, 2012, p. 16).

Las características que hemos citado en este apartado han sido recogidas dentro del concepto de dramaturgia institucional: el control pormenorizado que los teatros ejercen sobre todos los detalles de una representación ahora centrada no solo en la calidad de una retransmisión concreta, sino también en las posteriores posibilidades comerciales que permite su digitalización (Steichen, 2009, pp. 24-30; 2011, p. 449). Dicho control se extiende a los sistemas de producción, a los modos de representación en la gran pantalla, así como a los nuevos comportamientos que se quiere que el espectáculo provoque en la audiencia (Anderson, 2011, pp. 7-8).

\section{Aspectos sociológicos de la ópera en los cines}

Las características que hemos descrito en el apartado anterior otorgan a la ópera en los cines una identidad cultural distintiva. Hemos de estudiar ahora la identidad del público que se congrega en torno a ella.

En los últimos años, tanto los académicos como los organismos culturales se han esforzado por medir el comportamiento del público musical (Kolb, 2005, pp- 91-112; 


\section{INNOVACIÓN TEÓRICA}

Abfalter, 2009; Rössel, 2011, pp. 83-103; Gunzerath, 2012, pp. 99-106; Taneja \& Mamoria, 2012, pp. 121-140). En el caso de la ópera, el análisis de las audiencias en los cines todavía se considera un terreno de estudio joven y poco concluyente (Swanson, Davis \& Zhao, 2008, pp. 300-323). Los primeros análisis intentan averiguar, sobre todo, si en el medio-largo plazo la ópera mediatizada hará crecer la asistencia al espectáculo original; si provocará un descenso de las audiencias presenciales; o si sencillamente constituirá un modo de consumo artístico complementario (Zomerdijk \& Voss, 2011, p. 67; Speed, 2012; Vladica \& Davis, 2013， p. 5).

Por lo que han podido comprobar los estudios, el perfil medio de los asistentes es el de hombres y mujeres que superan los 45 años de edad. Constituyen un público homogéneo que procede mayoritariamente de la audiencia consolidada del espectáculo en vivo, al que se suma un número pequeño de asistentes atraídos de forma puntual por la curiosidad que les causa el evento (Berini, 2011). Asimismo, según la investigación de audiencias que Florin Vladica y Charles H. Davis realizaron en Canadá, Australia y Rumania, a partir de producciones operísticas neoyorkinas y londinenses, la mayor parte de los asistentes tienen estudios universitarios e ingresos económicos medios o elevados (2013). En apariencia, muchos de los espectadores de la ópera en los cines se muestran leales a este tipo de representaciones, que frecuentan una media de dos o tres veces al año.

Conocido, al menos a grandes rasgos, el perfil de la audiencia que asiste a la ópera en las salas de cine, el interés de los organismos se centra, sobre todo, en conocer elementos como la percepción de valor que de estos espectáculos construye dicha audiencia. Presentamos, a continuación, las conclusiones más importantes a las que hemos llegado tras estudiar las investigaciones realizadas hasta el momento.

\subsection{Gratificación elevada}

La mayor parte de los análisis sobre la percepción de valor destacan la elevada gratificación que experimentan los públicos operísticos en el cine. Quienes asisten de forma habitual a las salas -en especial aquellos públicos ya familiarizados previamente con el arte- conciben el fenómeno como una forma cultural legitimada y diferenciada de la original (Vladica \& Davis, 2013, p. 11). De hecho, son mayoría los que dicen estar 
en desacuerdo con la imagen, para ellos preconcebida, que se tiene del negocio: una versión disminuida o reducida del espectáculo en directo (Vladica \& Davis, 2013, p. 8).

Como principales variables que influyen en la elevada satisfacción de los asistentes a este tipo de consumo cultural mediatizado, los estudios citan el crecimiento educativo, la estética, la recreación personal, la interacción social y, sobre todo, el entretenimiento (Swanson, Davis \& Zhao, 2008, pp. 300-323; Bakhshi, Mateos-García \& Throsby, 2010, pp. 1-11; Barker, 2012). No obstante, si el evento es percibido de forma positiva, lo es principalmente porque ofrece nuevas posibilidades de disfrutar de la ópera que son difíciles o imposibles de obtener en la representación en vivo. Como ventajas, los asistentes destacan el acceso a las representaciones de ciudades cosmopolitas y lejanas - como Nueva York o Londres-, el bajo coste, el ahorro en los desplazamientos y la comodidad de la perspectiva privilegiada que ofrece el ojo de la cámara frente a la posición fija de los teatros (Vladica \& Davis, 2013, p. 4-13).

\subsection{Sensación de privilegio y sofisticación}

Es un hecho relevante que la experiencia en los cines sea considerada como similar o incluso como más refinada que la experiencia en el teatro. El público asiste con cierto orgullo y sentimiento de exclusividad al cine, además de con una sensación de sofisticación, vinculada al espacio en el que tiene lugar la representación (Steichen, 2011, p. 453; Vladica \& Davis, 2013, p. 10) ${ }^{10}$. Sin embargo, la sensación de privilegio no parece ser el motivo principal para optar por la ópera retransmitida en los cines: quienes así lo hacen, manifiestan su predisposición a priorizar el consumo de ópera en TV o DVD, en los casos en que en tales opciones domésticas se mantienen la calidad propia del HD.

Asimismo, gracias al carácter sofisticado y artificioso que posee la ópera, y gracias a la mayor accesibilidad que ofrecen las salas de cine con respecto a los teatros, el espectáculo mediatizado es especialmente apto para atraer a las nuevas miradas de los públicos potenciales que, por motivos culturales, económicos o geográficos no se han iniciado aun en el arte (Benzecry, 2011). 


\section{INNOVACIÓN TEÓRICA}

\subsection{Traslado de convenciones sociales}

La elevada aceptación por parte del público asistente y la percepción de la condición refinada del evento posibilitan que muchas de las convenciones de interacción social que se producen en los teatros sean trasladados a las salas de cine. En ellas suelen producirse las mismas reacciones colectivas que en el teatro original: aplausos en los intermedios, risas o comentarios entre los asistentes, etc. (Morris, 2010, p. 96-119). En ocasiones, el público de la sala de cine se comporta de una forma más formal que el del teatro, lo cual refuerza la idea de que siente que forma parte del espectáculo original, pues respeta sus convenciones y participa activamente en la representación (Sheppard, 2006, pp. 383-387; Heyer, 2008, pp. 591604). Ciertamente, para algunos autores, elementos compartidos como la risa o los aplausos constituyen fuertes manifestaciones del efecto comunidad (Speed, 2012, p. 102). Se ha tratado de explicar este efecto como una prueba del sentido colectivo que puede tener para los públicos la asistencia a los cines y se ha entendido que su fundamento estaba constituido por convenciones heredadas tanto de la función social de la ópera como del propio medio cinematográfico (Speed, 2012, p. 89).

\subsection{Comportamientos dispares en las salas}

Los estudiosos reconocen una disparidad de comportamientos del público, por ejemplo en aquellos campos relacionados con el atuendo o con las reacciones dentro de las salas cinematográficas. Algunos autores han conceptualizado con el término popcorn opera la presencia de actos espontáneos propios del cine entre los asistentes a una ópera en pantalla, por ejemplo, comer palomitas de maíz (Lacasa-Mas \& Villanueva, 2011, pp. 65- 74; Speed, 2012, pp. 111-114). Es un hecho que en la ópera retransmitida en las salas de cine conviven hábitos del público que son heterogéneos o incluso contradictorios, algo que, en el fondo, no hace sino manifestar que las retransmisiones de un arte refinado en un espacio popular implican una cierta paradoja. El término popcorn expresa bien el problema: mientras que los asistentes más familiarizados con las viejas tradiciones del arte aseguran que comer palomitas en una retransmisión de ópera vulnera y banaliza el consumo del arte, otros públicos manifiestan que solo es perjudicial en términos de escucha, ya que provoca ruido en la sala. De momento solo una minoría de los asistentes considera que la ópera debería convivir con comida y bebida durante el espectáculo, así 
como con atuendos desenfadados (Speed, 2012, pp. 112-113). Todo apunta a que las prácticas sociales que se acaben imponiendo serán distintas en cada región y dependientes de las tradiciones y normas culturales generales que se den en ellas. No cabe olvidar, de todas maneras, que el sentido elitista de la ópera está desapareciendo, no solo en las salas de cine, sino, más que en ningún otro sitio, en los propios teatros.

\subsection{Crecimiento del sentido de comunidad}

Las instituciones de la ópera, basadas en la tradición propia de la época de esplendor de su arte (Roselli, 1998, pp. 450, 451), promueven con su espectáculo un proceso simbólico y ritualizado de comunicación, que fomenta la participación colectiva y la experiencia compartida de la audiencia (Carey, 1989, p. 18). Como podría suceder en los teatros, asistentes a la ópera en los cines, el sentido comunitario les permite conocer a otros miembros de la audiencia, de gustos e inquietudes similares (Benzecry, 2011; Speed, 2012, p. 92). El sentido de comunidad también hace que los distintos niveles de gratificación musical, artística y social que se despiertan en cada miembro del público dependan, al menos en parte, del que experimenta la audiencia como un todo (Pitts, 2005, pp. 257-269).

Además, las personas que asisten al espectáculo mediatizado sienten que forman parte no solo del público que se ha congregado en la sala de cine, sino también del que llena el teatro. La experiencia que viven en la sala queda potenciada por la identificación con los intérpretes, los creadores y el público de la obra original, presentes en el teatro. Eso es posible gracias a herramientas que ya incorporaban la televisión o el vídeo, y que ahora resultan magnificadas en la gran pantalla de cine: los planos generales del teatro, de los públicos o los planos detalle de la orquesta, entre otros ejemplos ${ }^{11}$.

De igual modo, los públicos presenciales son conscientes de la existencia de cámaras que conectan a audiencias virtuales y masivas, dispersas por todo el mundo, lo cual prolonga su sensación de comunidad hasta una escala mundial (Anderson, 2011, p. 8). Así, a pesar de que las retransmisiones en HD dejen parcialmente de lado los rituales y convenciones tradicionales de la ópera en vivo, el evento operístico en los cines sigue basándose en la emulación de un ritual comunitario, amante de las artes clásicas (Glevarec \& Pinet, 2008, pp. 215-238). 


\subsection{Sensación de pérdida respecto al vivo}

El público que asiste a los cines experimenta en el evento mediático un sentido de pérdida respecto al original. Es consciente de que el objetivo de la cámara muestra siempre una imagen parcial de la representación. Percibe también que la profundidad, los colores y las formas se pierden parcialmente, debido a que la apreciación cinematográfica carece de una tridimensionalidad completa (Jung, 1990; Speed, 2012, pp. 110-111).

Ese sentido de pérdida modifica algunas de las reacciones del público operístico. La expresión personal de las emociones constituye un buen ejemplo de ello: mientras que en algunos títulos tradicionalmente se ha aceptado como algo natural que los hombres lloren en el teatro (Heyer, 2008, p. 595), en la ópera mediatizada la expresión de los sentimientos en presencia de otros miembros del público son menos frecuentes o explícitas, quizá porque el clima que se crea en el cine es menos emocional y participativo que el que surge en el teatro (Vladica \& Davis, 2013, p. 4). De todas maneras, los analistas todavía no han establecido si, en relación con la expresión de los sentimientos, las proyecciones en los cines promueven un cierto aislamiento, que no se da en los teatros (Anderson, 2011, p. 9).

\section{Conclusiones}

En 2016, el éxito de las retransmisiones operísticas en directo para los cines significa la consumación de los tradicionales intentos de relación de este arte musical con los medios de comunicación.

A pesar de distinguirse claramente del espectáculo original y de, al mismo tiempo, quedar vinculado intrínsecamente a él, la ópera disfrutada en una sala de cine consigue reinterpretarlo de forma sincera, respetuosa y auténtica. En consecuencia, es una forma de representación no solo compatible con la ópera original, sino especialmente apta para establecer sus propias relaciones artísticas y verdaderas con los públicos (Scannell, 1996, pp. 60-67).

El evento mediático constituido por la retransmisión de la ópera en cines permite fidelizar a las audiencias musicales, porque en él se produce un traslado de 
Las industrias convergentes y la ópera en los cines... | 15

INNOVACIÓN TEÓRICA

convenciones - artísticas y sociales - del espectáculo en vivo a las salas de exhibición, una condición necesaria para que el público más fiel a la música pueda reconocer sensaciones análogas a las que está acostumbrado a vivenciar en los teatros. Al hibridar convenciones artísticas y sociales, provenientes tanto de la ópera como del cine, el espectáculo está consiguiendo que la audiencia sienta, perciba y se comporte de manera distinta. Parece ser, sin duda, un buen camino para constituir un público propio: unos espectadores operófilos que gracias a él enriquecen su experiencia y unos espectadores mediáticos que se pueden adherir con mayor facilidad a la ópera como arte musical y mundo de referencia, al vivirlo en un contexto cinematográfico, más cercano a su realidad cotidiana.

En definitiva, la consolidación en el contexto artístico de la ópera retransmitida en los cines está en camino de quedar garantizada. Si bien sus cualidades mediáticas no sirven para pronosticar con seguridad la dirección artística o comercial que ambas industrias adoptarán, sí ayudan a entender muchos de los actuales cambios que está habiendo en sus públicos. En ellos se ha de apoyar cualquier estrategia de futuro. En el espectáculo retransmitido las audiencias no se sitúan en espacios entendidos como estrictamente operísticos o cinematográficos, sino más bien en un "espacio entre convenciones". Ese estado poco definido, al menos por el momento, brinda a ambas industrias una gran oportunidad de avanzar conjuntamente, no solo en términos artísticos, sino también sociológicos.

\section{Notas}

[1] Según el informe de las empresas IHS Screen Digest y Event Cinema Association, publicado en 2013, los contenidos operísticos dominan la oferta alternativa en las salas de cine europeas. En el caso de Gran Bretaña la ópera constituye el 39,7\% del consumo de retransmisiones en HD. Los porcentajes de temática operística en cines de otros países europeos también son altos. Véase, por ejemplo, los de Rusia (56,9\%), Francia (35,2\%) o Irlanda (35,6\%) (Rosser, 2013).

[2] Con estos términos se designan las retransmisiones de ópera para salas de cine, llevadas a cabo, en directo y alta definición, desde teatros como The National English Opera (ENO), El Gran Teatre del Liceu o The Metropolitan Opera House de Nueva York (Met).

[3] De los tradicionales contenidos mediáticos bajo demanda —-tales como la ópera filmada, la ópera en VHS o la televisión-ópera - se pasa a la creación de un gran contenido único que los organismos de ópera ofrecen a los cines. Muchas veces el teatro programa la obra original tratando de armonizar su diferencia horaria con las salas de cine, repartidas por todo el mundo (Speed, 2012, p. 2).

DOI: ri14.v15i1.979 | ISSN: 1697-8293 | Año 2017 Volumen 15 N$^{\circ} 1$ | ICONO14 


\section{INNOVACIÓN TEÓRICA}

[4] En términos generales, el streaming constituye un método de envío de flujos de información de vídeo a través de internet. Aunque su calidad es cada vez mejor, el streaming aun presenta complicaciones relacionadas, por ejemplo, con el ancho de banda, la pérdida de datos o las demoras (Sciara, 2004, p. 4).

[5] El Palco Digital permite disfrutar de distintos servicios de pago a los suscriptores, tales como el visionado doméstico de las transmisiones en directo producidas en alta definición mediante live streaming desde el teatro. Su videoteca ofrece, bajo demanda, obras grabadas en alta definición en el Teatro Real, así como contenidos adicionales que permiten profundizar en el conocimiento de las distintas piezas operísticas. Consultar: https://www.palcodigital.com; http://www.teatro-real.com/es.

[6] Las primeras retransmisiones en HD se realizaron en el año 2003, en Alemania y Holanda, de la mano de Robert y Julie Borchard-Young. Consistieron en la difusión de conciertos de música instrumental (Speed, 2012, p. 44). En nuestro país las primeras pruebas se llevaron a cabo en 2004. Fueron emisiones de ópera para algunos cines de Cataluña, realizadas gracias a la colaboración de L'Anella Cultural de ISCAT y el Gran Teatre del Liceu. Esta iniciativa partió de un proyecto educativo preexistente, surgido en 2001, denominado 0pera Oberta. Este último constituyó un negocio pionero en el mundo, de carácter colaborativo entre las universidades, los teatros y el I2CAT en Cataluña. A grandes rasgos, Opera Oberta ofrece a espacios educativos, como colegios y universidades, la proyección de espectáculos, en directo y en diferido, gracias al uso de medios audiovisuales. Consultar: http://www.rtve.es/alacarta/videos/opera-oberta/.

[7] En 2016 los espectáculos televisivos retransmitidos en salas cinematográficas constituyen un negocio internacional en auge. En el mercado español destacan las retransmisiones deportivas (fútbol, tenis, baloncesto...), el ballet y los conciertos en directo (como el de Alejandro Sanz, en 2010, ofrecido por la empresa Kinépolis).

[8] En la ópera retransmitida en los cines se emplean diversas técnicas propias de los directos televisivos para conseguir un efecto de cobertura total del evento y ampliar la visión comercial de estos espectáculos. La emisión simultánea del front y backstage o la división de la pantalla para mostrar varios contenidos a la vez son dos de ellas. Por otro lado, el empleo de material extra y la incorporación de presentadores, no reemplaza, sino que potencia la emoción que supone presenciar el espectáculo en directo. Dicha emoción es más intensa que aquella surgida de la apreciación de la obra en diferido (Johnson, 2008).

[9] Por ejemplo: en este tipo de espectáculos es común mostrar al realizador de la retransmisión de la ópera en la sala de control, rodeado de múltiples monitores, para reforzar su imagen de co-autor artístico. Se le intenta dotar de un prestigio similar al del director musical o al del director de escena (Anderson, 2011, p. 7).

[10] El estudio Value Propositions of Opera and Theater Live in Cinema, publicado por Florin Vladica y Charles H. Davis, recoge el hecho de que los asistentes a la ópera en el cine manifiestan vivir una experiencia cultural cool (2013, pp. 8, 9, 16).

[11] Unos 15 minutos antes de la representación, el público del cine es puesto en contacto con el público presencial mediante el uso de planos de las personas que van ocupando sus localidades, de detalles decorativos del teatro, y de la modulación de la intensidad de luz en la sala. Con ello se pretende comprometer al espectador virtual con el evento que está teniendo lugar en otro espacio, separado geográficamente (Anderson, 2011, p. 8). 


\section{Referencias}

Abfalter, D. (2009). Das Unmessbare messen?: Die Konstruktion von Erfolg im Musiktheater. Wiesbaden: Springer DE. doi:10.1007/978-3-531-92163-1

Anderson, A. (2011). Old Arts in New Media: Qualified Ontologies of 'Live' in the Age of Media 'Casting'. En, Global Conference on Performance: Visual Aspects of Performance Practice, 1-9. Prague.

Bakhshi, H., Mateos-Garcia, J., \& Throsby, D. (2010). Beyond Live: digital innvoation in the performing arts. London: NETSA, 1-11.

Barker, M. (2012). Live to Your Local Cinema: The Remarkable Rise of Livecasting. London: Palgrave Macmillan. doi: 10.1057/9781137288691

Benzecry, C. E. (2011). The opera fanatic: ethnography of an obsession. Chicago: University of Chicago Press. doi: 10.7208/9780226043432.001.0001

Berini, B. (2011). Una historia oral con B. Berini/Entrevistador: autores del departamento audiovisual y de documentación del Gran Teatre del Liceu. Barcelona.

Carey, J. W. (1989). Communication as culture: Essays on media and society. Boston: Unwin Hyman.

Cashin, C. (2010). Mediating the Live Theatrical and Operatic Experience: NT Live and the Met: Live in HD (Doctoral dissertation, NUI, 2010 at Department of Music, UCC).

Castells, M. (1997). La era de la información. Economía, sociedad y cultura (Vol I: La sociedad red). Alianza Editorial. Madrid, 506. ISBN 84-206-4247-9.

D'Agostino, P. (2010). The digital stage. Opera production for cinema and other audiovisual formats, a conversation with. En International Workshop on Opera and Video. Valencia.

Dayan, D., \& Katz, E. (1992). Media events: The live broadcasting of history. United States of America: Harvard University Press.

Feldman, A. (2005). On the actuarial gaze: From 9/11 to Abu Ghraib. Cultural Studies, 19(2), 203-226.

Glevarec, H., \& Pinet, M. (2008). From liberalization to fragmentation: a sociology of French radio audiences since the 1990s and the consequences for cultural industries theory. Media, Culture \& Society, 30(2), 215-238. 


\section{INNOVACIÓN TEÓRICA}

Gunzerath, D. (2012). Current trends in US media measurement methods. International Journal on Media Management, 14(2), 99-106.

Heyer, P. (2008). Live from the Met: Digital Broadcast Cinema, Medium Theory, and Opera for the Masses. Canadian Journal of Communication, 33, 591-604.

Horowitz, I. L. (2009). Mass, Class, and Audience: Beyond the Glenn Gould Problem. Modern Age, 51(1), 6-14.

Husak, W. (2004). Economic and other considerations for Digital Cinema. Signal Processing: Image Communication, 19(9), 921-936. doi: http://dx.doi. org/10.1016/j.image.2004.06.006

Jacob, E. (2006). Cineplex Entertainment Lifts the Curtains on the 'Metropolitan Opera: Live in $\mathrm{HD}^{\prime}$ at Select Canadian Theatres. CCNMatthews Newswire. Recuperado de http://www.highbeam.com/doc/1P2-13745362.html

Jung, J. F. (1990). Le relachêment narratif dans le système de la captation. Opera e Televisione. $2^{\circ}$ Seminario Internazionale. Roma: IRTEM.

Kolb, B. M. (2005). Marketing for cultural organizations: new strategies for attracting audiences to classical music, dance, museums, theatre \& opera. Cork: Thomson Learning, 91-112.

Lacasa-Mas, I., \& Villanueva, I. (2011). La digitalización audiovisual de la ópera: nuevos medios, nuevos usos, nuevos públicos. Telos: Cuadernos de comunicación e innovación, (88), 65-74.

Lacasa-Mas, I., \& Villanueva, I. (2012). Actualización de la ópera y sus nuevos modelos de comunicación digital. El profesional de la información, 21(4), 413418. doi: http://dx.doi.org/10.3145/epi.2012.jul.14

Lipovetsky, G., \& Serroy, J. (2009). La pantalla global. Cultura mediática y cine en la era hipermoderna. Barcelona: Anagrama.

Maddaleno, J. (2015). Rising Alternative la ópera en cine en todo su esplendor. Opera Actual, 87, recuperado de: http://operaactual.com/contenidos/ reportajes/100-rerpotajes-articulos/354-rising-alternative-la-opera-en-cineen-todo-su-esplendor.html

Morris, C. (2010). Digital diva: opera on video. The Opera Quarterly, 26(1), 96-119. Pitts, S. (2005). What makes an audience? Investigating the roles and experiences of listeners at a chamber music festival. Music and letters, 86 (2), 257-269. Rombes, N. (2009). Cinema in the Digital Age. New York: Wallflower Press. 
Rössel, J. (2011). Cultural capital and the variety of modes of cultural consumption in the opera audience. The Sociological Quarterly, 52(1), 83-103.

Scannell, P. (1996). Radio, television and modern life: A phenomenological approach. London: Blackwell.

Sciara, D. R. (2004). Fundamentos de video streaming. línea]. Available: http:// iie. fing. edu. uy/ense/asign/codif/material/monografias/2004-01. pdf [último acceso: 13-08-2014], 01-2004.

Shaw, D. A. (2008). Technoculture: The key concepts. New York: Berg Sheil.

Sheppard, A. W. (2007). Review of the Metropolitan Opera's new HD movie theater broadcasts. American Music, 25(3), 383-387.

Speed, B. (2012). Opera Enormous: Arias in the Cinema (Doctoral dissertation). United States of America: University of Maine.

Steichen, J. (2009). The Metropolitan Opera Goes Public: Peter Gelb and the Institutional Dramaturgy of The Met: Live in HD. Music and the Moving Image, 2(2), 24-30.

Steichen, J. (2011). HD 0pera: A Love/Hate Story. The Opera Quarterly, 27(4), pp. 443-459.

Steichen, J. (2012). Recordings in review. The Yale Review, 100(3), 204-209.

Swanson, S. R., Davis, J. C., \& Zhao, Y. (2008). Art for art's sake? An examination of motives for arts performance attendance. Nonprofit and Voluntary Sector Quarterly, 37(2), 300-323.

Taneja, H., \& Mamoria, U. (2012). Measuring media use across platforms: Evolving audience information systems. International Journal on Media Management, 14(2), 121-140.

The Metropolitan 0pera. (2010). Annual Reports; 2007- 2008 and 2008-2009. Recuperado http://www.metoperafamily.org/uploadedFiles/Met0pera/about_ the_met/annual_report/ANNUALreport.pdf

Vanderbeeken, R. (2011). The screen as an in-between. Foundations of Science, 16(2-3), 245-257. doi: http://dx.doi.org/10.1007/s10699-010-9191-x

Villanueva Benito, I. (2014). La mediatización audiovisual de la ópera como proceso de apertura a nuevos públicos: El caso de la Obra Don Giovanni de WA Mozart. Tesis Doctoral.

Vladica, F., \& Davis, C. H. (2013). Value propositions of opera and theater live in cinema. Dubai: Canadian University of Dubai, 1-31. 
20 | Isabel Villanueva Benito e Iván Lacasa-Mas

Zallo, R. (2011). Paradojas de la Cultura Digital. Telos (88). Recuperado de http:// sociedadinformacion.fundacion.telefonica.com/seccion=1266\&idioma=es ES\&id $=2011072809010001 \&$ activo $=6$. do

Zomerdijk, L. G., \& Voss, C. A. (2011). NSD Processes and Practices in Experiential Services. Journal of Product Innovation Management, 28(1), 63-80. 